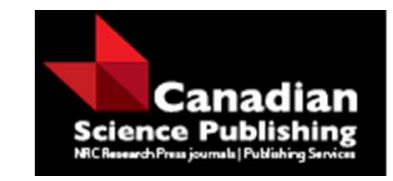

Canadian Journal of Physics

Revue canadienne de physique

\title{
Investigations of argon and neon abnormal glow discharges in the presence of metastable atom density with fluid model
}

\begin{tabular}{|r|l|}
\hline Journal: & Canadian Journal of Physics \\
\hline Manuscript ID & cjp-2015-0692.R2 \\
\hline Manuscript Type: & Article \\
\hline Date Submitted by the Author: & 03-Apr-2016 \\
\hline Complete List of Authors: & $\begin{array}{l}\text { Alili, Tahar; Electrotechnique } \\
\text { Bouchikhi, Abdelaziz; Electrotechnique } \\
\text { Rizouga, Mohamed ; Electrotechnique }\end{array}$ \\
\hline Keyword: & $\begin{array}{l}\text { Metastable atom density, Abnormal glow discharge, Fluid model, Input } \\
\text { Data, Boltzmann's equation }\end{array}$ \\
\hline
\end{tabular}




\title{
Investigations of argon and neon abnormal glow discharges in the presence of metastable atom density with fluid model
}

\author{
Tahar Alili ${ }^{1}$, Abdelaziz Bouchikhi ${ }^{2, a}$, Mohamed Rizouga ${ }^{1}$ \\ ${ }^{1}$ University of Sciences and Technology of Oran, USTO-MB, 31000, Algeria \\ ${ }^{2}$ University of Saïda, Faculty of technology, Department of electrical engineering, Saïda \\ 20000, Algeria
}

Résumé: Cet article est consacré à une analyse de la décharge luminescente anormale dans l'argon et le néon dans le régime continu en présence d'atome métastable. Dans le cas de l'argon, la pression est entre 133.32 et 330.32 $\mathrm{Pa}$, la tension est de 250 jusqu'à $400 \mathrm{~V}$. Dans le cas du néon, la pression est de $399.92 \mathrm{~Pa}$ (3 Torr) et la tension est de 300 à $500 \mathrm{~V}$. Dans l'ordre de ce travail une analyse est effectuée de la décharge luminescente dans le cas les données de base sont obtenues par la résolution de l'équation de Boltzmann avec l'approximation de multitermes (BMA) et dans le cas les données de base sont obtenues par le code BOLSIG+. Par conséquences, les résultats obtenus sont différents et plus particulièrement sont différents dans la région cathodique. Les distributions spatiotemporelles des densités électronique et ionique, du potentiel et du champ électriques, l'énergie de l'électron et la densité d'atome métastable sont présentées. Le modèle utilisé est le fluide d'ordre deux dans une géométrie monodimensionnelle. Le rôle de la présence d'atomes métastables dans le modèle est très clair à cause de l'augmentation du terme source d'ionisation par le processus d'ionisation d'atome métastable et le processus chimio-ionisation. Les résultats sont validés par ceux obtenus dans la littérature théorique et expérimentale.

\begin{abstract}
In this manuscript an investigation of a DC argon and neon abnormal glow discharges with metastable atom density is presented. The values of pressure between $133.32 \mathrm{~Pa}$ and $330 \mathrm{~Pa}$, voltage range from 250 to 400 $\mathrm{V}$ in the case of argon gas. In the case of neon gas the pressure has the value of $399.92 \mathrm{~Pa}$ (3 Torr) and the voltage range from 300 to $500 \mathrm{~V}$. In the frameworks, an analysis of abnormal glow discharge characteristics is carried out in the case of input data taken from the Boltzmann equation in multi term approximation (BMA), and in the case of input data obtained from BOLISG+ code. As conclusion of these differences of input data in the same gas the output results are different and it appears in the cathodic region. The spatio-temporal distributions of electron and ion densities, the potential and electric field, the mean electron energy and the metastable atom density are shown. A 1D fluid model is used to solve self-consistently the first three moments of the Boltzmann's equation coupled with the Poisson's equation. The role of the presence of metastable atom density in the fluid model is clearly because of the dominated of ionization processes by both stepwise and penning ionizations. Our results are validated with those obtained by both recent paper and experimental results.
\end{abstract}

(Some figures in this article are in colour only in the electronic version)

Mots Clés: Densité d'atome métastable, Décharge luminescente anormale, Fluide modèle, Données de Base

Keywords: Metastable atom density, Abnormal glow discharge, Fluid model, Input Data 
PACS: 52.65.-y Plasma simulation -52.80.Hc Glow; corona

\section{Introduction}

A glow discharge is a plasma, including appropriately the same electrons and ion densities bigger than the gas density. In its simplest form, the plasma is generated by a parallel plate electrodes put in low pressure gas 10 to $1000 \mathrm{~Pa}$, as well as subject to the voltage range from 200 to $2000 \mathrm{~V}$ and causes electrical breakdown of the gas, thus creating positive ions and electrons. The positive ions are accelerated towards the cathode by the intense electric field in the face of it, provoking new electrons under the bombardment cathode by positive ions. The electrons are in turn accelerated away from the cathode, and acquire energies sufficiently high for ionization and excitation. The excitation and de-excitations processes are responsible for the characteristic light of the "glow" discharge. The ionization processes generate new ions and electrons, essential to maintain the glow discharge.

Plasma is extensively used in the technological applications of dusty plasmas and in the microelectronics industry, to etch, deposit, and modify thin films ${ }^{[1-4]}$. The understanding of charged-particle transport in the sheaths is of paramount importance for a better control and optimization of industrial reactors. In spite of the widespread use of DC discharges in microelectronic manufacturing, our understanding of the physical and chemical mechanism of the discharge is still incomplete ${ }^{[5]}$. As an example, the influence of the input data for the same gas on the output results is not published in existing literature. As well as the influence of metastable lifetime in the discharge.

In this work, an investigation is made concerning the role of argon and neon metastable atoms in the discharge. Metastable atoms have been studied by several authors, both experimentally and theoretically. Metastable densities can experimentally be measured by optical absorption techniques. In theoretical work, a balance equation, including different production and loss terms is constructed to calculate the metastable densities. Experimental measurements were performed, for example, for helium gas as a function of discharge conditions by Browne and Dunn ${ }^{[6]}$, for argon gas in a microwave boosted glow discharge by Uzelac and Leis ${ }^{[7]}$, and for Ne in an RF glow discharge by Eckstein et al. ${ }^{[8]}$. In the work of Smith et al. ${ }^{[9]}$ only relative absorption signals of Ar metastable atoms as a function of current and pressure were measured. In the work of Ferreira et al. ${ }^{[10]}$ and Strauss et al. ${ }^{[11]}$ Ar metastable densities were measured in a Grimm-type glow discharge and in the afterglow of a pulsed discharge, respectively, and some mechanisms for the formation of Ar metastable atoms were suggested. Ar metastable densities have also been measured by Ferreira and Ricard. ${ }^{[12]}$ and by Ferreira et al. ${ }^{[13]}$.

A comparison was made with Ar metastable densities calculated from a coupled-electron-metastable-atom model. A comparison between experiment and calculated metastable densities was also carried out by Kubota et al. ${ }^{[14]}$ for $\mathrm{He}$ in a DC and RF glow discharge. Hardy and Sheldon ${ }^{[15]}$ have studied He, Ne and Ar gases. Den Hartog et al. ${ }^{[16,17]}$ have studied He gas. Lymberopoulos and Economou ${ }^{[18]}$ have developed a combined fluid model for the electrons, argon ions, and argon metastable atoms in order to investigate the effect of metastable atoms in the discharge. In Refs. ${ }^{[19-24]}$ rate constants of a number of collision processes responsible for the destruction of metastable atoms were obtained by combining balance equations with the measured time-dependent variation of the metastable densities or by analyzing the dependence of the decay constants upon pressure.

In the latter work, Shumova et al. ${ }^{[25]}$ have studied the effect of metastable neon atoms in a positive column of glow discharge with dust particles. Fedoseev, and Sukhinin ${ }^{[26]}$ have studied the influence of metastable argon atoms and dust particles on gas discharge plasma. 
The aim of this work is to present, influence of the discharge characteristic in the case of input data taken from the Boltzmann equation in multi term approximation (BMA), and in the case of input data obtained by BOLSIG+ code. We note that both these approaches are widely used. For simulations of positive column of glow discharge, Sukhinin et al. ${ }^{[27]}$ used the first approach, while Vasilyak et al. ${ }^{[28]}$ used the second approach. In section 2, the model discharge is described, it contains the initial and boundary condition as well as the numerical procedure. In section 3, the results are discussed for argon discharge. In section 4, the validity of the model is given. In section 5, Influence of the input Data obtained from BOLSIG+ on the argon discharge has been presented. In section 6, the properties of the neon discharge with input data taken from BOLSIG+ are shown. Finally, the conclusion of the work is given in section 7 .

\section{Discharge Modeling}

Our discharge modeling is based on the first three moments of the Boltzmann transport equations. The Continuity equations and momentum transfer equations of electrons, positively charged ions and metastable atom. The energy equation is given only for electrons and the Poisson equation is the determination of the electric potential ${ }^{[29]}$.

The kinetic scheme, including the processes in our discharge are mentioned in the Table 1.

Then, the model in the case of the one-dimensional Cartesian geometry considered the corresponding basic system of partial differential equation reads:

$$
\begin{aligned}
& \frac{\partial n_{e}}{\partial t}+\frac{\partial \phi_{e}}{\partial x}=n_{e}\left(n_{o} K_{o}^{i o}+n_{m} K_{m}^{i o}\right)+n_{m} n_{m} K^{c i}, \\
& \frac{\partial n_{+}}{\partial t}+\frac{\partial \phi_{+}}{\partial x}=n_{e}\left(n_{o} K_{o}^{i o}+n_{m} K_{m}^{i o}\right)+n_{m} n_{m} K^{c i}, \\
& \frac{\partial n_{m}}{\partial t}+\frac{\partial \phi_{m}}{\partial x}=n_{e}\left(n_{o} K_{o}^{m}-n_{m} K_{m}^{o}-n_{m} K_{m}^{i o}\right)-2 n_{m} n_{m} K^{c i}-\frac{n_{m}}{\tau_{m}}, \\
& \frac{\partial \varepsilon_{e} n_{e}}{\partial t}+\frac{\partial \phi_{e \varepsilon}}{\partial x}=-e \phi_{e} E+\varepsilon^{m} n_{e} n_{m} K_{m}^{o}+\varepsilon^{c i} n_{m} n_{m} K^{c i} \\
& -n_{e} P^{e c}-n_{e}\left(\varepsilon^{m} n_{o} K_{o}^{m}+\varepsilon^{i o} n_{o} K_{o}^{i o}+\left(\varepsilon^{i o}-\varepsilon^{m}\right) n_{m} K_{m}^{i o}\right) \\
& \frac{\partial^{2} V}{\partial x^{2}}=-\frac{e}{\varepsilon_{o}}\left(n_{+}-n_{e}\right)
\end{aligned}
$$

Here $n_{e}, n_{+}, n_{m}, \phi_{e}, \phi_{+}$and $\phi_{m}$ are number densities, densities of transport flux of the electrons, ions and metastable atoms, respectively. $\mathrm{n}_{\mathrm{o}}$ is the constant background gas density, $\mathrm{K}_{\mathrm{o}}^{\mathrm{m}}$ is the rate coefficient of electronimpact excitation of ground state atoms, $\varepsilon^{m}=11.55 \mathrm{eV}$ is the energy loss of excited atoms, $\mathrm{K}_{\mathrm{o}}^{\text {io }}$ is the rate coefficient of electron-impact ionization of ground state atoms and $\varepsilon^{i o}=15.76 \mathrm{eV}$ is the energy loss of ionized atoms, $\mathrm{K}_{\mathrm{m}}^{\mathrm{io}}$ is the rate coefficient of electron-impact ionization of excited atoms with the energy $\operatorname{loss}\left(\varepsilon^{i o}-\varepsilon^{m}\right)$. 
$\mathrm{K}_{\mathrm{m}}^{\mathrm{o}}$ is the rate coefficient of de-excitation of excited atoms by electron collisions. $K^{c i}=8.1 \times 10^{-10} \mathrm{~cm}^{3} \mathrm{~s}^{-1}{ }^{[30]}$ is the rate coefficient of chemo-ionization processes with the energy gain $\varepsilon^{c i}=2 \varepsilon^{m}-\varepsilon^{i o} \cdot \tau_{\mathrm{m}}=1 \mu \mathrm{s}$ is the metastable lifetime. $\mathrm{P}^{\mathrm{ec}}$ is the energy loss per electron due to elastic collision of electrons with the background gas ${ }^{[31]}$. $\varepsilon_{\mathrm{e}}$ is the mean electron energy, $\phi_{\mathrm{e} \varepsilon}$ is the electron energy flux. $\mathrm{V}$ is the electrostatic potential, $E=-\partial V / \partial x$ is the electric field strength. $\varepsilon_{0}$ and e are the permittivity of free space and elementary charge, respectively.

Momentum transfer equations for electrons, ions, metastable atoms and electron energy ${ }^{[32-34]}$ are:

$$
\begin{aligned}
& \phi_{e}=-n_{e} \mu_{e} E-\frac{\partial D_{e} n_{e}}{\partial x}, \\
& \phi_{+}=n_{+} \mu_{+} E-\frac{\partial D_{+} n_{+}}{\partial x}, \\
& \phi_{m}=-D_{m} \frac{\partial n_{m}}{\partial x}, \\
& \phi_{e \varepsilon}=-n_{e} E \mu_{e \varepsilon}-\frac{\partial n_{e} D_{e \varepsilon}}{\partial x}
\end{aligned}
$$

Here $\mu_{\mathrm{e}}, \mu_{+}, \mathrm{D}_{\mathrm{e}}$ and $\mathrm{D}_{+}$are the electron, ion for mobilities and diffusion coefficients, respectively. $\mathrm{D}_{\mathrm{m}}$ is the metastable atom diffusivity where $\mathrm{n}_{\mathrm{o}} \mathrm{D}_{\mathrm{m}}=1.7 \times 10^{18} \mathrm{~cm}^{-1} \mathrm{~s}^{-1}{ }^{[19]}$. The ion mobility is taken from Phelps and Petrović ${ }^{[35]}$ and their ion diffusivity is calculated according to the Einstein's relation ${ }^{[36]}$. $\mu_{\mathrm{e} \varepsilon}$ and $\mathrm{D}_{\mathrm{e} \varepsilon}$ are the mobility and diffusivity of electron energy transport.

The coefficients for electrons ${ }^{[37]}$ in argon as dependences on the mean electron energy are obtained from INP Greifswald for direct comparison with the results published by Becker et al. ${ }^{[29]}$.

\subsection{Initial and boundary conditions}

The discharge is established between two parallel plate electrodes and the radius of the electrode is assumed to be much greater than the electrode gap and the distributions of the physical properties are almost uniform along the radial direction. The powered electrode which initiates the discharge at $\mathrm{x}=0 \mathrm{~cm}$, is considered as the cathode $\left(\mathrm{V}_{\text {cathode }}=-\mathrm{V}_{\mathrm{DC}}\right)$. The grounded electrode has been taken at $\mathrm{x}=1 \mathrm{~cm}$, is considered as the anode $\left(\mathrm{V}_{\text {anode }}=0\right)$. In time $\mathrm{t}=0$, the electron, ion and metastable atom densities are assumed constant and equal to $10^{3} \mathrm{~cm}^{-3}$. A mean electron energy has been taken $1 \mathrm{eV}$.

Assuming a predominant field-driven flux close to the cathode the relation $\partial D_{+} n_{+} / \partial x=0$ has been employed for the positive ion density $\forall \mathrm{t}>0$, while vanishing metastable atom density, i.e., $\mathrm{n}_{\mathrm{m}}=0$ has been prescribed at the cathode. At the anode, the electron density and the metastable atoms are assumed to be zero. The electron flux parting the cathode is computed by the expression $\phi_{e}(x=0, t)=-\gamma \phi_{+}(x=0, t) \forall t>0$, the mean electron energy is assumed to be $5 \mathrm{eV}$ at the cathode ${ }^{[35]}$ and the gas temperature is equal to $273 \mathrm{~K}$ in the discharge. 


\subsection{Numerical procedure}

For the transport equations of the electron, ion and electron energy a finite difference method has been used. For This technique the exponential approximation has been taken into account ${ }^{[36,38-41]}$. The Poisson and metastable atom equations are also discretized spatially with the finite difference method. The discretization of the terms of the time with the finite difference method on the right position has been employed . Therefore, each discretized equation is represented by a tridiagonal matrix, which are resolved by Thomas's technique.

\section{Results and discussion of argon discharge}

In this paragraph, we will survey the spatio-temporal development of the abnormal glow discharge in the presence of metastable atom density. The applied potential at the cathode is $-400 \mathrm{~V}$. The constant value for the secondary electron yield is $0.06^{[35]}$. The gas pressure is $133.32 \mathrm{~Pa}$. The neutral species density is determined from the gas pressure and temperature with the ideal gas law. The time step $\Delta \mathrm{t}=10 \mathrm{ps}$ and a uniform subdivision of the space interval in 250 elements, have been used.

Figure. 1 represents the temporal evolution of the potential (a), the densities of electrons (b), ions (c) and metastable atom (d), electric field (e) and the mean electron energy (f). We observe that the discharge is characterized by three zones: the first one occupied the time simulation between $10^{-11}$ and $9 \times 10^{-6} \mathrm{~s}$, the second one occupied the time simulation between $9 \times 10^{-6}$ and $3 \times 10^{-5} \mathrm{~s}$, the final zone occupied the time simulation between $3 \times 10^{-5}$ and $3.6 \times 10^{-5} \mathrm{~s}$.

For the first zone, we remark that the electrons, ions numbers and metastable atom densities are approximately indistinguishable. Consequently, the net space charge density is negligible. The electric potential is characterized the Laplace form because of the net space charge density that is present. Hence, the electric field is quasi constant. The mean electron energy is also constant, because the electric field is present.

In the second zone, we observe a pseudo appearance of the cathodic region, this is typified by an importance of ion number density and less significant to the electron number density. This is explained to the accelerate electron species that spread a great deal faster than ion species and move rapidly from the cathodic region. Therefore the quantities $\left(\mathrm{n}_{\mathrm{e}}-\mathrm{n}_{+}\right)$is significant which influence the potential as a chute. Consequentially, the electric field is important. The latter acquires an important energy of electron species. We observe, that the metastable atom density is significant. This discharge is maintained by secondary emission processes as well as the presence of metastable atom density. Before $t=3 \times 10^{-5} \mathrm{~s}$ we observe a pseudo appearance of negative glow, where it is characterized by the same electron and ion densities. Therefore the net space charge density is negligible and hence the electric potential and electric field are constants. Consequentially, the metastable density is reduced. In the final zone, we observe three different regions' the anode and cathode regions and the plasma region. The anode region is typified by ion number density, that is less imperative compared to the electron number density. In this zone we observe the convergence of all physical properties of the discharge at the time $3.6 \times 10^{-5} \mathrm{~s}$.

\subsection{Influence of the gas pressure and voltage}

In this paragraph, we are going to examine the influence of the gas pressure and voltage on the argon discharge. 
For this reason, the voltage is fixed at $250 \mathrm{~V}$ and we are going to change the gas pressure. For the influence applied voltage to the discharge, us to be fixed the pressure gas at $133.32 \mathrm{~Pa}$.

Figure. 2 (a) presents the metastable atoms density curves as a function of pressure in the stationary state. The metastable atom density increases with growing pressure. For higher pressure the gas density increase, which the electron diffusion coefficient turns out to be less and the volume of the plasma increase which the sheaths of the anode and cathode becomes short. These situations of the charged particle influence on the metastable atoms curve in the stationary state, i.e. the cathodic region is filled with the metastable atom and electron densities, which accelerated the ion species in the presence of electric field.

Figure. 2 (b) presents the metastable atoms density curves as a function of voltage in the stationary state. For higher voltage, the ionization and excitation processes augment and the charged particle becomes increase in the steady-state. Which also the metastable atom curve turns out to be increase.

The maximum of the metastable atom density varies between $2.47 \times 10^{10}$ and $6.63 \times 10^{11} \mathrm{~cm}^{-3}$. We compared these results with computed values found in the literature ${ }^{[9,10,12,15]}$. Depending on discharge conditions, all these values vary between $2 \times 10^{10}$ and $5 \times 10^{13} \mathrm{~cm}^{-3}$. Therefore, Our computed values around in the correct range of magnitude order. We note that the values of current densities are $0.137,0.508$ and $0.843 \mathrm{~mA} / \mathrm{cm}^{2}$ corresponding to the pressures of 133.32, 250.32 and 330.32 Pa, respectively.

Figure. 3 shows the current-voltage characteristics in the steady state. The results obtained from the database of BMA compared to those experimental results ${ }^{[42,43]}$. We note that the results obtained from the database of the BMA are in good agreement compared to those experimental results ${ }^{[42]}$ and ${ }^{[43]}$.

\section{Validity of the model}

Figure. 4 proves the comparison between our results and those given by Becker et al. ${ }^{[29]}$ (a) electron and ion densities, (b) electric potential and electric field, (c) metastable atom density and (d) mean electron energy. These comparisons confirm validity of our 1D code. The major differences between our results and those given by Becker et al. are illustrated in the Table 2.

We note that the same discharge has been treated by Fiala et al. ${ }^{[44]}$, where the hybrid model has been used in two dimensional geometry. We note that the results obtained by Fiala et al, it was almost identical to our results. In particular, the electric field at the cathode is $675 \mathrm{~V} / \mathrm{cm}$ and the maximum of particle densities is $1.1 \times 10^{9} \mathrm{~cm}^{-3}$ for applying potential that is equal to $126.3 \mathrm{~V}$. Thus, our fluid model in the presence of metastable atoms is equivalent to the hybrid model for these discharge conditions. In addition, our model gives both distributions, metastable atom density and mean electron energy.

\section{Influence for input data of argon abnormal glow discharge}

In this paragraph, we are going to present the characteristic of the argon plasma discharge in the case of input data calculated by BOLSIG + code ${ }^{[45]}$. We note that the previous results are given with input data calculated by multi term approximation of the Boltzmann equation. We note that the previous results are similar when are computed without using the rate coefficients $\mathrm{K}_{\mathrm{m}}^{\mathrm{o}}$ and $\mathrm{K}_{\mathrm{m}}^{\mathrm{io}}$. The exception is the metastable atom density, which is influenced by these coefficients, i.e. the stepwise ionization is negligible, compared to the both ionization of the ground state 
atoms and chemo-ionization processes. For this reason we computed the characteristics of the argon abnormal glow discharge without using $\mathrm{K}_{\mathrm{m}}^{\mathrm{o}}$ and $\mathrm{K}_{\mathrm{m}}^{\mathrm{io}}$ coefficients. The applied potential at the cathode is $-250 \mathrm{~V}$. The gas pressure is $133.32 \mathrm{~Pa}$. The secondary electron emission coefficient is 0.06 .

Figure. 5 presents the particle density profiles (a), metastable atom density (b) and mean electron energy (c) in the steady state. Comparison of the results is given in the figure. 4 These distributions show clearly the influence of input data of BOLSIG+ on the properties of argon abnormal glow discharge. In particular, the cathodic region represented in the figure. 4 (a) is absolutely different from the cathodic region presented by the figure. 5 (a). We note that the same discharge conditions (pressure, voltage,...) corresponding to multi and two terms approximations, the results are really different.

Table. 3 gives the major difference between input data of BOLSIG+ and of multi term approximation.

Figure 6 represents the comparison between experimental results ${ }^{[46,47]}$ and our results obtained from database of BOLSIG + software for $\mathrm{pd}=2$ Torr $\mathrm{cm}$. We note that the experimental results ${ }^{[46,47]}$ are given for inter-electrodes spacing of $1 \mathrm{~cm}$ and the diameter of the electrode is $8 \mathrm{~cm}$. We also note that the results given by reference ${ }^{[46]}$ its almost different from the results given by reference ${ }^{[47]}$ due to the experimental conditions of secondary electron emission coefficient. We observe that the our results obtained from database of BOLSIG+ software are in good agreement with the experimental results ${ }^{[46]}$.

\subsection{Influence of the metastable lifetime on the properties of argon abnormal glow discharge}

We note that the previous calculations are made for a metastable lifetime equal to $1 \mu \mathrm{s}{ }^{[29]}$, we note that this value has been supposed by Becker et al. ${ }^{[29]}$. Figure. 7 shows the influence of the metastable lifetime on the spatial distribution of metastable atom density in the stationary state. For this reason we employed a value of metastable lifetime equal to $38 \mathrm{~s}$ of the experiment ${ }^{[48]}$ and a theoretical value ${ }^{[49]}$, equal to $56 \mathrm{~s}$. We observe that the maximum of metastable atom density increases from $7.76 \times 10^{9}$ to $2.249 \times 10^{11} \mathrm{~cm}^{-3}$. We note that this influence is noticed only for metastable atom density and all properties of argon abnormal glow discharge remain unchanged. Thus, the employing of the artificial or experimental value of metastable lifetime is unimportant for abnormal glow discharge characteristics.

\section{Properties of the neon discharge with input data from BOLSIG+}

In this paragraph, we are going to examine the properties of neon abnormal glow discharge with input data from BOLSIG+. The applied potential is 300 Volt. The secondary electron emission coefficient is 0.26 [1]. The gas pressure is 3 Torr. Other parameters are mentioned in the Appendix A. Figure. 8 presents the profiles of electrons and ions volume number (a), metastable atom density (b) and (c) current density as a function of applied potential in the steady state. We note that the maximum of metastable atom density is $1.615 \times 10^{11} \mathrm{~cm}^{-3}$. The electric field at the cathode attains the value of $1696.08 \mathrm{~V} / \mathrm{cm}$. We note that the maximum of mean electron energy is $46.30 \mathrm{eV}$ in the cathodic region and the value of neon current density is $0.1851 \mathrm{~mA} / \mathrm{cm}^{2}$. We conclude that the fluid model by introducing metastable atom density is very interesting for treating the abnormal glow discharge characteristic for many pure gases and gas mixtures. 


\section{Conclusion}

In order to study the effect of metastable atom density, a second order fluid electric model has been developed in the case of a DC low-pressure Ar and Ne abnormal glow discharges. The Poisson equation for the potential and electric field is coupled to the first three moments of the Boltzmann's conservation equations neglecting inertia of the charged particles. In the framework of the local energy approximation, the basic data used in this work are determined by Becker et al. in the case of multi term approximation of Boltzmann equation (BMA) and from BOLSIG+ code. The role of metastable atom density in the discharge is clear for investigation into side of plasma glow discharge for many pure gases and gas mixtures. We note that the abnormal glow discharge is maintained by secondary electron emission and the presence of metastable atom density in this case of discharge.

\section{Acknowledgments}

The authors express their gratitude to Markus M Becker (Greifswald-Germany) for helpful discussions.

\section{REFERENCES}

[1] Chapman B. 1980, Glow Discharge Processes. John Wiley Sons, New York

[2] Harrison W W. 1988, Glow Discharge Mass Spectrometry. Wiley, New York

[3] Marcus R K. 1993, Glow Discharge Spectroscopies. Plenum Press, New York

[4] Donkó Z, Hartmann P, Kutasi K. 2006, Plasma Sources Sci. Technol, 15: 178

[5] Boef J P. 1987, Phys. Rev. A, 36: 2782

[6] Browne P G, Dunn M H. 1973, J. Phys. B, 6: 1103

[7] Uzelac N I , Leis F. 1992, Spectrochim. Acta, 47B: 877

[8] Eckstein E W, Coburn J W , Kay E. 1975, Int. J. Mass Spectrom. Ion Phys, 17: 129

[9] Smith R L, Serxner D, Hess K R. 1989, Anal. Chem, 61: 1103

[10] Ferreira N P, Strauss J A, Human H G C. 1982, Spectrochim. Acta, 37B: 273

[11] Strauss J A, Ferreira N P, Human H G C. 1982, Spectrochim. Acta, 37B: 947

[12] Ferreira C M, Ricard A. 1983, J. Appl. Phys. 54: 2261

[13] Ferreira C M, Loureiro J, Ricard A. 1985, J. Appl. Phys, 57: 82

[14] Kubota T, Morisaki Y, Ohsawa A, et al. 1992, J. Phys. D, 25: 613

[15] Hardy K A, Sheldon J W. 1982, J. Appl. Phys, 53: 8532

[16] Den Hartog E A, Doughty D A, Lawler J E. 1988, Phys. Rev. A, 38: 2471

[17] Den Hartog E A, O'Brian T R, Lawler J E. 1989, Phys. Rev. Lett, 62: 1500

[18] Lymberopoulos D P, Economou D J. 1993, J. Appl. Phys, 73: 3668

[19] Phelps A V, Molnar J P. 1953, Phys. Rev, 89: 1202

[20] Phelps A V. 1955, Phys. Rev, 99: 1307

[21] Ellis E, Twiddy N D. 1969, J. Phys. B, 2: 1366

[22] Copley G H, Lee C S. 1975, Can. J. Phys, 53: 1705

[23] Tachibana K. 1986, Phys. Rev. A, 34: 1007 
[24] Kolts J H, Setser D W. 1978, J. Chem. Phys, 68: 4848

[25] Shumova V V, Polyakov D N, Vasilyak L M. 2014, Plasma Sources Sci. Technol, 23: 065008

[26] Fedoseev A V, Sukhinin G I. 2011, Ukr. J. Phys, 56: 1272

[27] Sukhinin G I, Fedoseev A V, Antipov S N, et al. 2013, Phys. Rev. E, 87: 013101

[28] Vasilyak L M, Polyakov D N, Shumova V V. 2013, Contrib. Plasma Phys, 53: 432

[29] Becker M M, Loffhagen D, Schmidt W. 2009, Comp. Phys. Com, 180: 1230

[30] Kolokolov N B, Kudrjavtsev A A, Blagoev A B. 1994, Phys. Scripta, 50: 371

[31] Sigeneger F, Winkler R. 1999, IEEE Trans. Plasma Sci, 27: 1254

[32] Belenguer Ph, Boeuf J P. 1990, Phys. Rev. A, 41: 4447

[33] Donkó Z. 1998, Phys. Rev. E, 57: 7126

[34] Marié D, Kutasi K, Malovié G, et al. 2002, Eur. Phys. J. D, 21: 73

[35] Phelps A, Petrović Z. 1999, Plasma Sources Sci. Technol, 8: R21

[36] Bouchikhi A. 2012, Plasma Sci. Technol, 14: 965

[37] Becker M M, Loffhagen D. 2013, AIP ADVANCES, 3: 012108

[38] Scharfetter D L, Gummel H K. 1969, IEEE Trans. Electron Devices, 16: 64

[39] Bouchikhi A, Hamid A, Flitti A, et al. 2008, Acta Electrotehnica, 48: 404

[40] Bouchikhi A, Hamid A. 2010, Plasma Sci. Technol, 12: 59

[41] Stankov M N, Petković M D, Marković V Lj et al. 2014, Rom. J. Phys, 59: 328

[42] Stefanovic' I, Petrovic' Z Lj. 1997, Jpn. J. Appl. Phys. Part 1, 36: 4728

[43] Rozsa K, Gallagher A, Donkó Z. 1995, Phys. Rev, E 52: 913

[44] Fiala A, Pitchford L C, Boef J P. 1994, Phys. Rev. E, 49: 5607

[45] Hagelaar G, Pitchford L. 2005, Plasma Sources Sci. Technol, 14: 722

[46] Petrović Z, Jelenković B, Phelps A. 1994, Communication privée

[47] Jelenković B, Rózsa K, Phelps A. 1993, Phys. Rev. E, 47: 2816

[48] Katori H, Shimizu F, 1993, Phys. Rev. Lett, 70: 3545

[49] Small-Warren N E, Chow-Chiu L Y. 1975, Phys. Rev. A, 11: 1777

[50] Zinner M, Spoden P, Kraemer T, et al. 2003, Phys. Rev. A, 67: 010501(R)

[51] Frost L S. 1957, Phys. Rev, 105: 354

[52] Ricard A. 1969, Jphs, 30: 556

[53] Sheverev V A, Stepaniuk V P, Lister G G. 2002, J. Appl. Phy, 92: 3454

[54] Gaens W, Bogaerts A. 2014, J. Phys. D. Appl. Phys, 47: 079502

E-mail ${ }^{\text {: }}$ bouchikhiabdelaziz1@yahoo.fr

TEL: 00-213-7-74-15-94-42 
Table 1. Kinetic scheme of processes

\begin{tabular}{|l|l|}
\hline Processes & Name of processes \\
\hline $\mathrm{Ar}+\mathrm{e}^{-} \rightarrow \mathrm{Ar}^{+}+2 \mathrm{e}^{-}$ & Ionization \\
$\mathrm{Ar}+\mathrm{e}^{-} \rightarrow \mathrm{Ar}_{\mathrm{m}}^{*}+\mathrm{e}^{-}$ & Excitation \\
$\mathrm{Ar}_{\mathrm{m}}^{*}+\mathrm{e}^{-} \rightarrow \mathrm{Ar}+\mathrm{e}^{-}$ & De-excitation \\
$\mathrm{e}^{-}+\mathrm{Ar}_{\mathrm{m}}^{*} \rightarrow \mathrm{Ar}^{+}+2 \mathrm{e}^{-}$ & Stepwise ionization \\
$\mathrm{Ar}_{\mathrm{m}}^{*}+\mathrm{Ar}_{\mathrm{m}}^{*} \rightarrow \mathrm{Ar}^{+}+\mathrm{e}^{-}+\mathrm{Ar}$ & Chemo-ionization \\
\hline
\end{tabular}

Table. 2 The major differences between our results and those given by Becker et al.

\begin{tabular}{|c|c|}
\hline Becker et al [29] & Our results \\
\hline $\begin{array}{l}\text { Stabilized finite element method for the } \\
\text { transport and energy equations are used. }\end{array}$ & Scharfetter and Gummel scheme is used \\
\hline $\begin{array}{l}\text { The applied potential at the cathode is } \\
\mathrm{V}_{\mathrm{DC}}\left(1-\mathrm{e}^{-\mathrm{t} / \tau}\right) \text { and } \tau=1 \mathrm{~ns}\end{array}$ & The applied potential at the cathode is $V_{D C}$ \\
\hline The steady state is attained at $10^{-4} \mathrm{~s}$ & The steady state is attained at $3.6 \times 10^{-5} \mathrm{~s}$ \\
\hline $\begin{array}{l}\text { The computations were performed on a } \\
3 \mathrm{GHz} \text { CPU and typically took about four } \\
\text { hours to reach the steady state. }\end{array}$ & $\begin{array}{l}\text { The calculations are carried out in a } \\
\text { personal computer. It typically takes about } \\
\text { five hours to reach the steady state }\end{array}$ \\
\hline The parametric studies are not presented & $\begin{array}{l}\text { The parametric studies of gas pressure and } \\
\text { applied potential are presented }\end{array}$ \\
\hline
\end{tabular}

Table. 3 The major differences between input Data of BOLSIG+ and those given by multi term approximation.

\begin{tabular}{ll}
\hline Input-Data (multi term approximation) & Input-Data (BOLSIG+) \\
\hline $\begin{array}{l}\text { Boltzmann equation is solved in the 8-term } \\
\text { approximation }\end{array}$ & $\begin{array}{l}\text { Boltzmann equation is solved in the } \\
\text { two-term approximation } \\
\text { The activated energy of } \mathrm{K}_{\mathrm{o}}^{\mathrm{m}} \text { is } \approx 3 \mathrm{eV}\end{array}$ \\
$\begin{array}{l}\text { The activated energy of } \mathrm{K}_{\mathrm{o}}^{\mathrm{m}} \text { is }<<3 \mathrm{eV} \\
\text { The activation energy of } \mathrm{K}_{\mathrm{o}}^{\text {io }} \text { is } \approx 5 \mathrm{eV}\end{array}$ & $\begin{array}{l}\text { The activated energy of } \mathrm{K}_{\mathrm{o}}^{\text {io }} \text { is }<<5 \mathrm{eV} \\
\text { Electron mobility is almost great }\end{array}$ \\
\hline
\end{tabular}



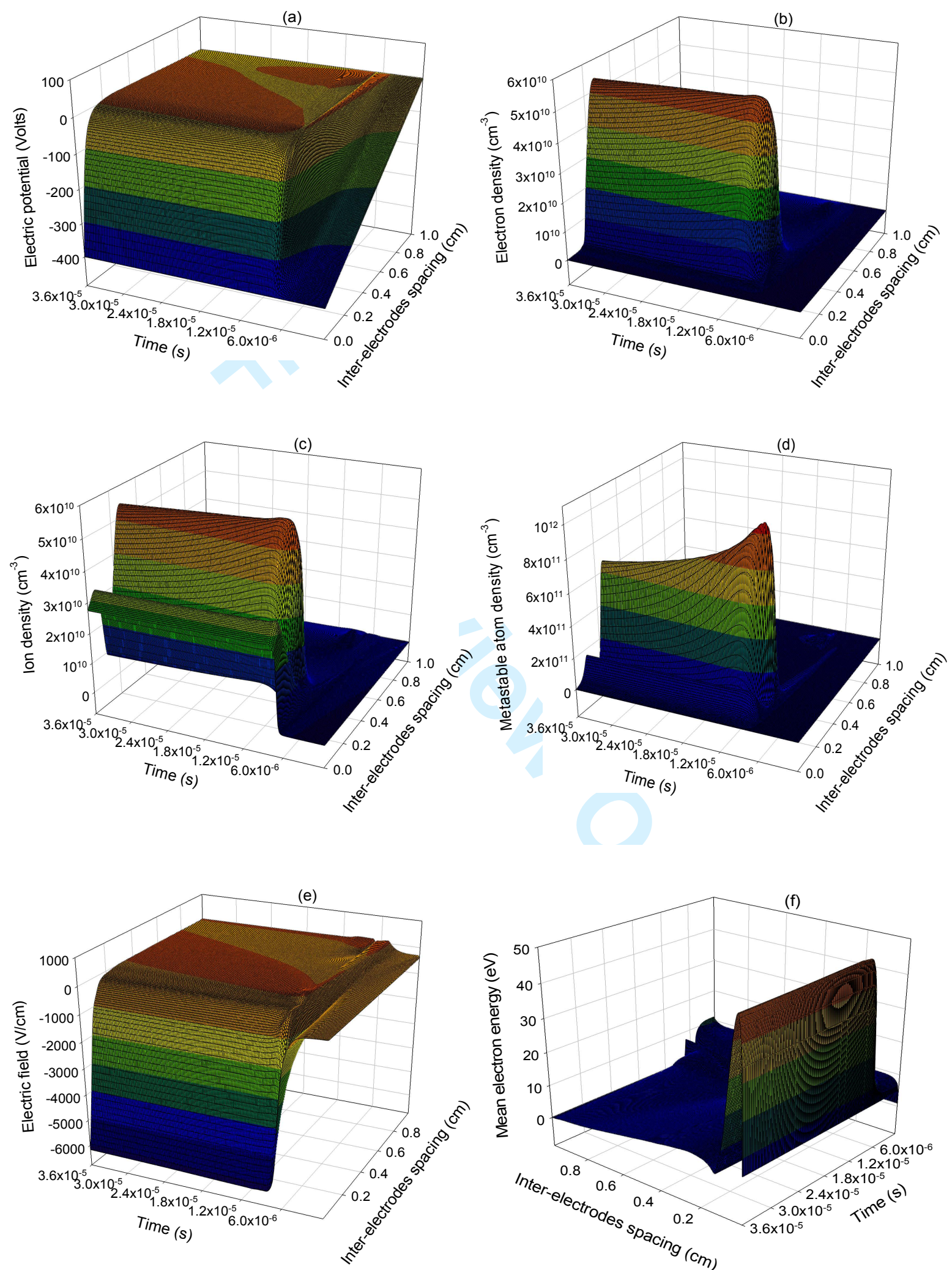

Figure. 1 Argon spatio-temporal distributions of electric potential (a), electrons volume number (b), ions volume number (c), metastable atom density (d), electric field (e) and mean electron energy (f) at $400 \mathrm{~V}$. 
(a)

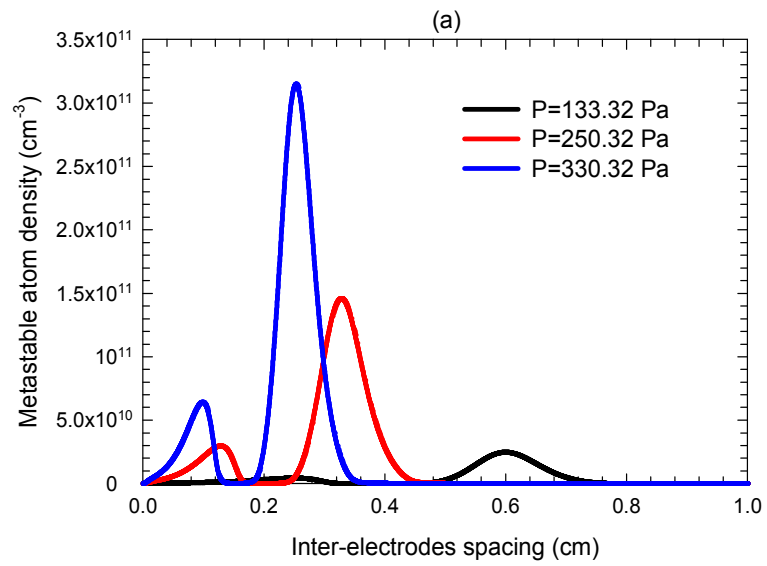

(b)

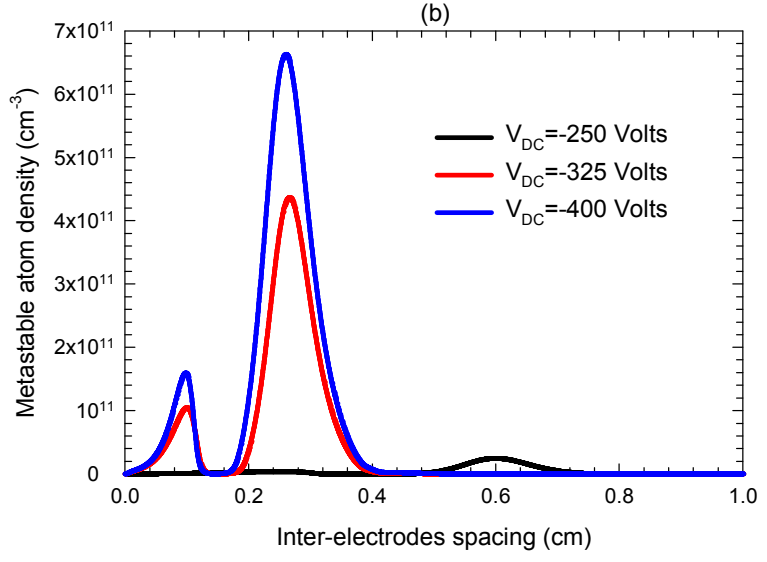

Figure. 2 Metastable atom densities as a function of pressure (a) and as a function of voltage (b) in the stationary state in argon gas

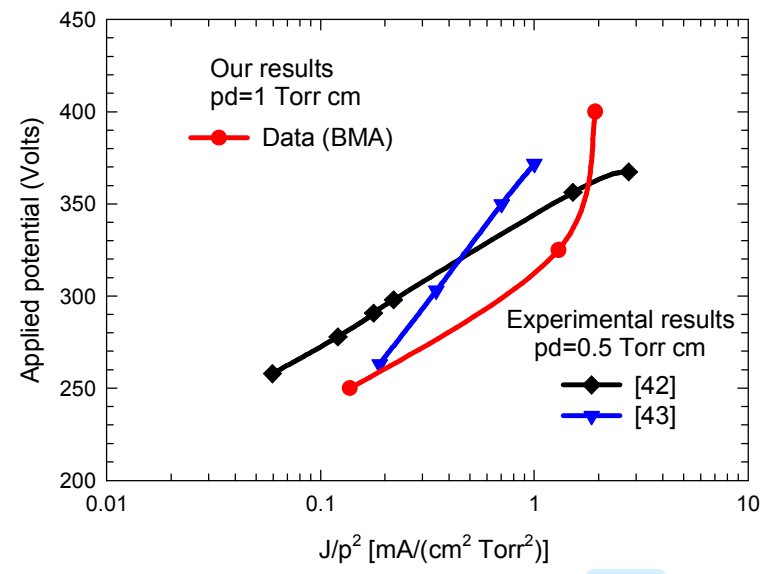

Figure. 3 Comparison between the results obtained by our calculation using a database of BMA for $\mathrm{pd}=1$ Torr $\mathrm{cm}$ and those given by experimental for $\mathrm{pd}=0.5$ Torr $\mathrm{cm}$ in Argon gas. 

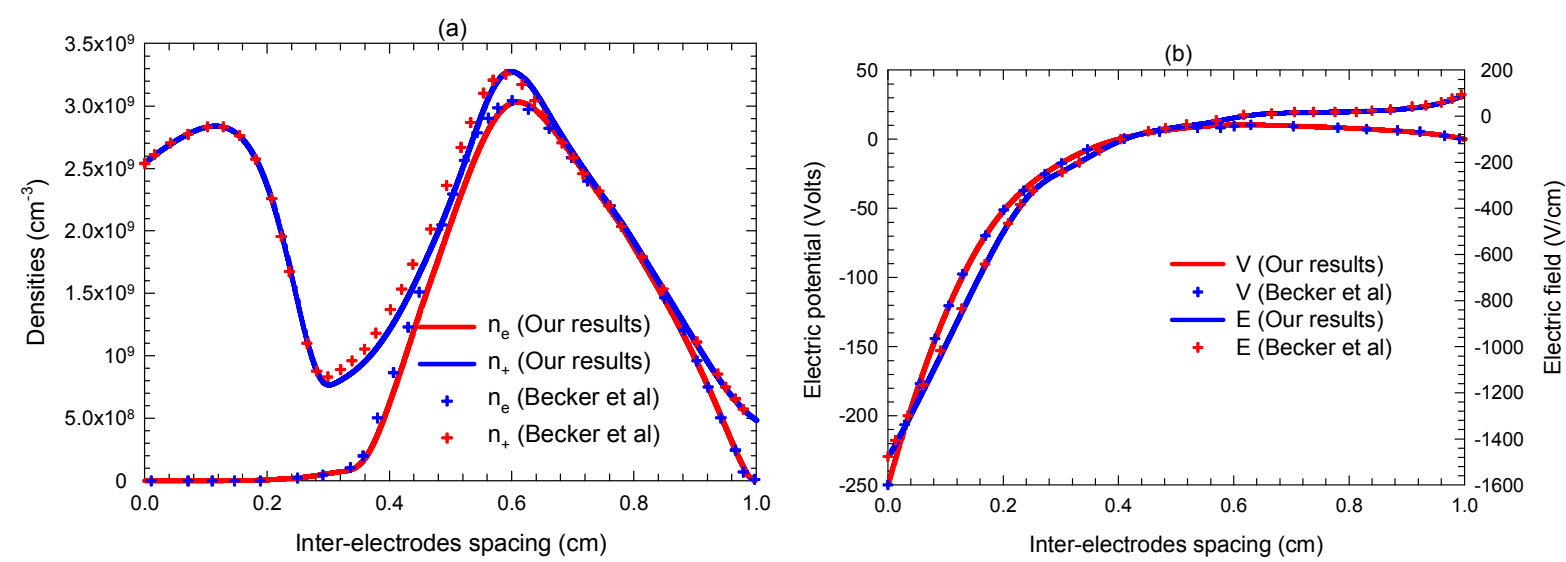

(c)


Figure. 4 Comparison between our results and those given by Becker et al (a) densities, (b) electric potential and electric field, (c) metastable atom density and (d) mean electron energy in the stationary state in argon gas.
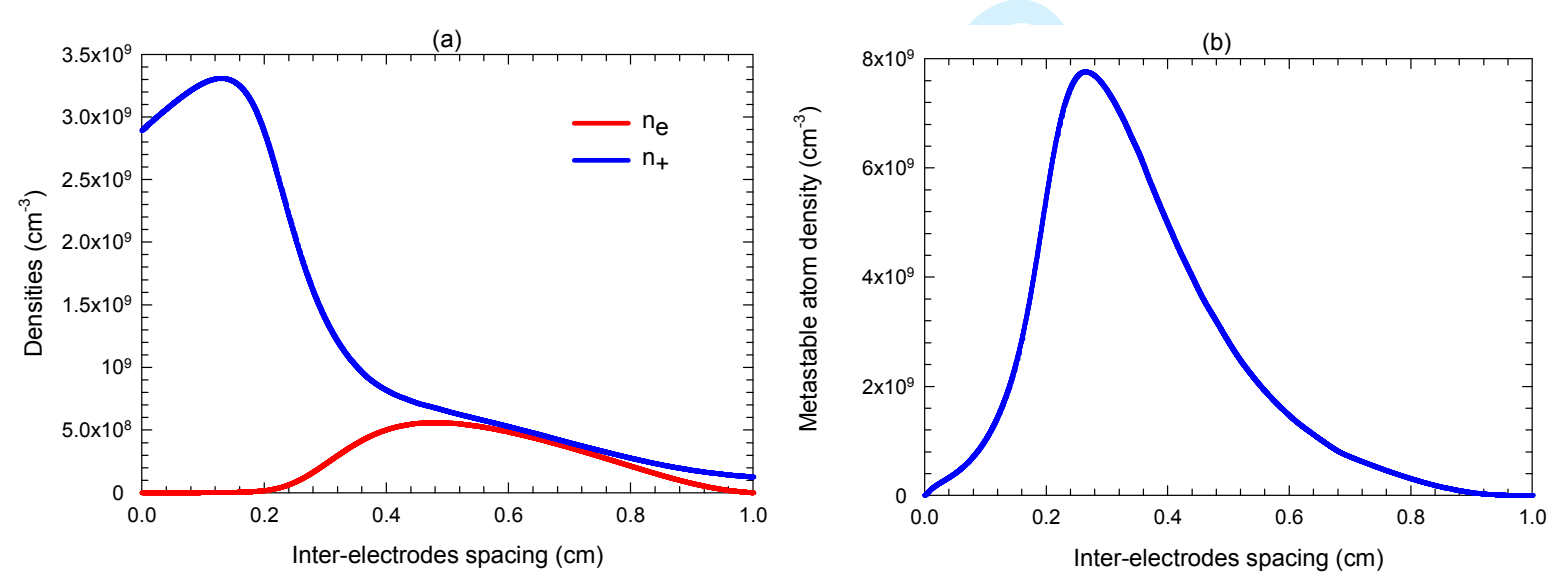


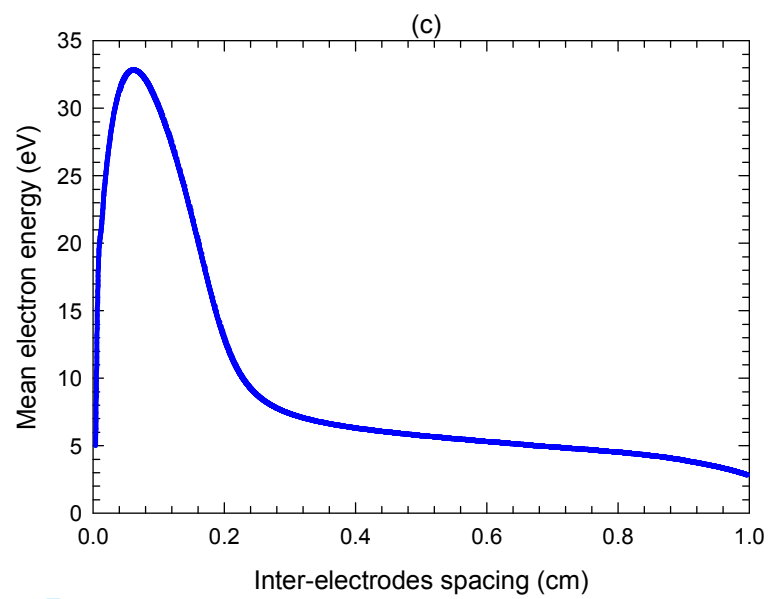

Figure. 5 Argon spatial distributions of (a) particle densities, (b) metastable atom density and (c) mean electron energy in the stationary state for input data of BOLSIG+.

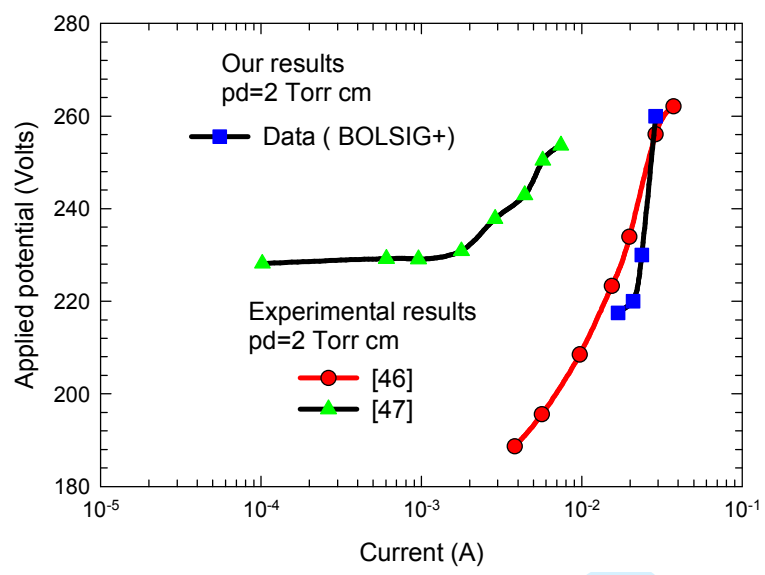

Figure. 6 Comparison between the results obtained by our calculation using database of BOLSIG + software for $\mathrm{pd}=2$ Torr $\mathrm{cm}$ and those given by experimental for $\mathrm{pd}=2$ Torr $\mathrm{cm}$ in argon gas

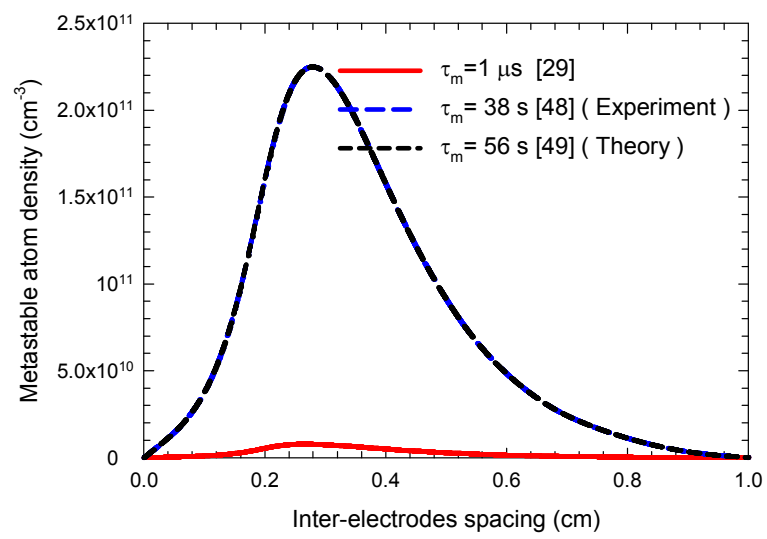

Figure. 7 Influence of the metastable lifetime on the Argon spatial distribution of metastable atom density in the steady state 

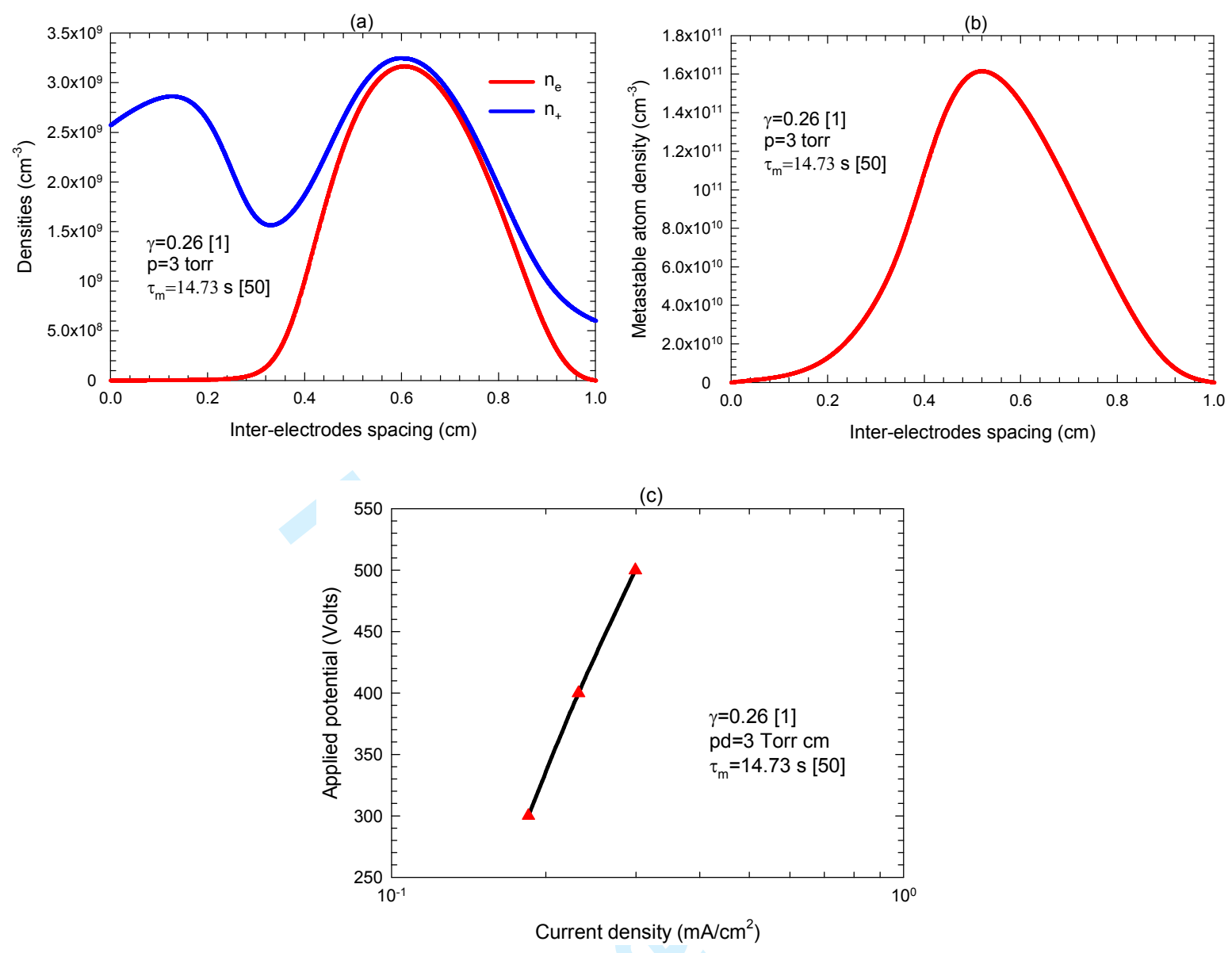

Figure. 8 Neon spatial distributions of (a) particle densities and (b) metastable atom density and (c) current density as a function of applied potential in the stationary state. 


\section{Appendix A}

The metastable lifetime of neon gas is $14.73 \mathrm{~s}^{[50]}$. the drift velocity of positive ion neon gas is: $\mathrm{W}_{+}=(11.27 \mathrm{E} / \mathrm{n}) /(1+0.01288 \mathrm{E} / \mathrm{n})^{0.5}(\mathrm{~m} / \mathrm{s}){ }^{[51]}$ where $\mathrm{E} / \mathrm{N}$ is in Td. Energy loss of an excited atom is 16.6 $\mathrm{eV}$. The diffusion coefficient of metastable atoms is $\mathrm{Dm}=150 \mathrm{~cm}^{2} \mathrm{~s}^{-1}$ torr ${ }^{[52]}$. The rate coefficient of chemoionization is $\mathrm{Kci}=3.6 \times 10^{-10} \mathrm{~cm}^{3} \mathrm{~s}^{-1}$ for $\mathrm{T}=310 \mathrm{~K}{ }^{[53]}$. The Ionization energy of neon gas is $21.56454 \mathrm{eV}$. The energy loss $\left(\mathrm{P}^{\mathrm{ec}}\right)$ per electron due to elastic collision of electrons with the background gas is determined according to ${ }^{[31,54]}$. 